\title{
A Note on Interstate Migration and Tax Burdens: New Evidence
}

Dr. Yu Hsing, Economics \& Business Research, Southeastern Louisiana University

\begin{abstract}
This study extends the work of Cebula (1990) and examines interstate in-migration for 48 contiguous states based on the 1990 Census data. We find that the 'optimal'value for the state and local tax burden is $\$ 1,943$ per capita. Interstate in-migration rates are likely to increase (decrease) given a change in tax burdens, if the current tax level is below (above) the optimal tax level. We also find that more sunshine, employment growth, and income encourage in-migration and that higher heating degree days, percent of metropolitan area population, and violent crime reduce in-migration.
\end{abstract}

\section{Introduction}

Migration has been studied extensively by prominent scholars. When state or local data are used, some of these variables include tax burdens (Tiebout, 1956; Cebula, 1990), employment growth (Muth, 1971; Nakosteen and Zimmer, 1980; Molho, 1984), income (Nakosteen and Zimmer, 1980), educational attainment (Sandell, 1977; Schlottmann and Herzog, 1981), urbanization (Navratil and Doyle, 1977), climate (Porell, 1982; Cebula, 1990), past migration (Molho, 1984; Herzog, Hofler, and Schlottmann, 1985), and others. Greenwood $(1975,1985)$ provides excellent reviews of the literature.

This paper extends the work of Cebula (1990) and examines the determinants of the interstate in-migration rate with an emphasis on the role of local and state tax burdens. The paper differs from some of the previous studies in several aspects. First, it is postulated that the relation between in-migration rates and tax burdens may be negative or positive, depending upon the level of tax burdens. It is possible that when tax burdens are relatively small, in-migration rates would not decline with an increase in tax burdens, as voters and consumers regard more basic government services as necessary. On the other hand, when tax burdens are relatively high and beyond the expected level, in-migration rates are likely to decline if more taxes are imposed. Second, several major socioeconomic variables such as employment growth, income, and crime are included in the model so that their impacts can be estimated. Third, the data come from the 1990 Census and are more recent. The data for tax burdens include both local and state taxes that are derived from own sources.
The paper is organized in the following manner. The theoretical framework is discussed in the second section. Data sources and regression results are presented and interpreted in the third section. A summary and concluding remarks are made in the last section.

\section{The Model}

Based on previous studies and human capital theory (Becker, 1962, 1975) to maximize expected future returns on migration, the interstate in-migration rate can be expressed as

$$
\begin{gathered}
\mathrm{MIG}_{\mathrm{i}}=\mathrm{f}\left(\mathrm{TAX}_{\mathrm{i}}, \mathrm{SUN}_{\mathrm{i}}, \mathrm{HDD}_{\mathrm{i}}, \mathrm{EMP}_{\mathrm{i}}, \mathrm{INC}_{\mathrm{i}}, \mathrm{EDU}_{\mathrm{i}}, \mathrm{MET}_{\mathrm{i}},\right. \\
\left.\mathrm{CRM}_{\mathrm{i}}\right)
\end{gathered}
$$

where

MIG = the in-migration rate defined as the percent of total in-migrants out of total population aged 5 and over between 1985 and 1990;

TAX = per capita state and local tax burdens;

SUN = percent of possible sunshine per year;

HDD = heating degree days;

$\mathrm{EMP}=$ the growth rate of labor employment during 1985-1990;

INC = per capita disposable personal income;

$\mathrm{EDU}=$ percent of population ages 25 and over with college degrees or higher;

MET $=$ percent of metropolitan area population;

$\mathrm{CRM}=$ violent crimes per 100,000 population;

$\mathrm{I}=$ a state. 
The migration rate is expected to vary positively with $\mathrm{SUN}_{\mathrm{i}}, \mathrm{EMP}_{\mathrm{i}}, \mathrm{INC}_{\mathrm{i}}$, and $E D U_{i}$, but negatively with $\mathrm{HDD}_{\mathrm{i}}$, $\mathrm{MET}_{\mathrm{i}}$, and $\mathrm{CRM}_{\mathrm{i}}$. The sign of tax burdens may be negative or positive. Voters and consumers may formulate an 'optimal' tax burden. They would not mind paying more taxes, if the existing tax is below this optimal amount. Residents are reluctant to pay more taxes, if the current tax burden is above this optimal tax. Employment growth represents the labor market condition. The unemployment rate is not used, as most research has indicated that it does not explain migration behavior as well as the employment growth variable does (Greenwood, 1985, p. 532). Per capita personal income may capture potential earnings in a destination state. The expected negative sign of $\mathrm{MET}_{\mathrm{i}}$ tests the hypothesis that recent migration pattern tends toward non-metropolitan areas (Greenwood, 1985). High violent crime deteriorates the quality of life and discourages in-migration.

\section{Data Sources and Results}

The sample consists of the 1990 Census data for 48 contiguous states. $\mathrm{MIG}_{\mathrm{i}}$ cam from the 1990 Census of Population: Social and Economic Characteristics, U.S. Census of Bureau. TAX $_{\mathrm{i}}$ was obtained from Government Finances, U.S. Bureau of the Census. TAX $\mathrm{T}_{\mathrm{i}}$ includes state and local property taxes, general sales taxes, selective sales taxes, individual income taxes, corporation net income taxes, license taxes, and others. $\mathrm{SUN}_{\mathrm{i}}$ and $\mathrm{HDD}_{\mathrm{i}}$ were taken from Climatography of the United States, U.S. National Oceanic and Atmospheric Administration. $\mathrm{HDD}_{\mathrm{i}}$ is a 30-year average ranging from 1961 to $1990 . \mathrm{EMP}_{\mathrm{i}}$ was from Employment, Hours, and Earnings, U.S. Bureau of Labor Statistics. $\mathrm{INC}_{\mathrm{i}}$ was from the Survey of Current Business, U.S. Bureau of Economics Analysis. EDU $\mathrm{ED}_{\mathrm{i}}$ came from U.S. Census of Population, CPH-L-96, U.S. Bureau of the Census. MET $\mathrm{M}_{\mathrm{i}}$ was from the Statistical Abstract of the United States, U.S. Bureau of the Census. $\mathrm{CRM}_{\mathrm{i}}$ cam from the Crime in the United States, U.S. Federal Bureau of Investigation.

An analysis of the date indicates that in 1990 top five states with the highest tax burdens per capita in order were New York $(\$ 3,337)$, New Jersey $(\$ 2,778)$, Connecticut $(\$ 2,667)$, Massachusetts $(\$ 2,469)$, and Minnesota $(\$ 2,348)$. Five states with the lowest tax burdens per capita were South Dakota $(\$ 1,489)$, Tennessee $(\$ 1,410)$, Alabama (\$1,364), Arkansas $(\$ 1,337)$, and Mississippi $(\$ 1,302)$.

Before presenting empirical results, the absence of heteroscedasticity is tested. Based on the Harvey and Glejser tests, the absence of heteroscedasticity can be rejected at the $1 \%$ level. Thus, the weighted least squares
(WLS) method assuming dependent variable heteroscedasticity is used to estimate equation (1). After trying several functional forms, the semi-log form is chosen because of better statistical outcomes. Because a number of states experienced negative employment growth, the level form is used for $\mathrm{EMP}_{\mathrm{i}}$. Variables defined above are added with a ' $L$ ' in the front to denote the logarithmic scale. The estimated regression is reported in equation (2). Note that the inclusion of $\operatorname{LTAX}_{\mathrm{i}}^{2}$ is to test if there exists a quadratic relation between $M_{1} G_{i}$ and $L_{T A X}$, as we discussed earlier. As shown, $60 \%$ of the variation of the interstate in-migration rate can be explained by the righthand-side variables. All the coefficients have the expected signs and are significant at the $5 \%$ or $1 \%$ level, except for the coefficient of $L E D U_{i}$, which has a correct sign but is insignificant. Specifically, interstate migration is positively correlated with percent of possible sunshine, employment growth, income, but negatively associated with heating degree days, percent of metropolitan area population, and violent crime.

$$
\begin{aligned}
& \mathrm{MIG}_{\mathrm{i}}=229.410 \mathrm{LTAX}_{\mathrm{i}}-15.149 \mathrm{LTAX}_{\mathrm{i}}^{2}+10.657 \mathrm{LSUN}_{\mathrm{i}}-1.805 \mathrm{LHDD}_{\mathrm{i}} \\
& \begin{array}{llll}
(3.088) & (-3.159) \quad(3.461) & (-2.093)
\end{array} \\
& \text { + 0.244 EMP }+ \text { + 9.254 } \mathrm{LINC}_{\mathrm{i}}+3.383 \mathrm{LEDU}_{\mathrm{i}}-3.886 \mathrm{LMET}_{\mathrm{i}} \\
& \begin{array}{llll}
(4.886) & (1.839) & (1.124) & (-2.499)
\end{array} \\
& \text { - 2.019 } \mathrm{LCRM}_{\mathrm{i}}-959.310, \mathrm{R}^{2}=0.595, \mathrm{LLF}=-109.896 \\
& (-2.186) \quad(-3.361)
\end{aligned}
$$

The coefficients of tax burdens show that interstate inmigration rates and tax burdens follow a quadratic relation. Taking partial derivative of $\mathrm{MIG}_{\mathrm{i}}$ with respect to LTAX $_{\mathrm{i}}$ in equation (2) and setting it equal to zero, we have $\partial \mathrm{MIG}_{\mathrm{i}} / \partial \mathrm{LTAX}_{\mathrm{i}}=229.41-2(15.149) \mathrm{LTAX}_{\mathrm{i}}=0$. Solving for $\mathrm{LTAX}_{\mathrm{i}}$, we obtain $\mathrm{LTAX}_{\mathrm{i}}=7.57$. Taking an anti-log, we have $\operatorname{TAX}_{i}^{*}=1,943$, which is the tax burden at the turning point for a maximum solution, because the second condition shows a negative value. It suggests that interstate in-migration rates have a positive (negative) relation with tax burdens if per capita local and state tax burden is below (greater than) $\$ 1,943$. In comparison, Cebula (1990) reports a negative relation between the migration rate for the retired people and the income tax variable.

\section{Summary and Conclusions}

We have examined the determinants of interstate inmigration rates based on the 1990 Census data for 48 states. To increase in-migration, state and local governments need to help create job opportunities with better compensation, emphasize the quality of education, and reduce violent crime. We have also shown that interstate in-migration rates and tax burdens exhibit a positive or a negative relation, depending upon whether 
the existing tax burden is less or greater than the optimal tax burden of $\$ 1,943$. An examination of the data indicates that twenty-six states had tax burdens below the amount of $\$ 1,943$ and that governments in these states may raise taxes to improve government services without experiencing declining interstate in-migration. On the other hand, twenty-two states had tax burdens greater than this amount, suggesting that they impose tax burdens beyond the optimal level. It is also interesting to note that a number of states had tax burdens which are close to the optimal level. These states and tax burdens in parentheses are Colorado $(\$ 1,960)$, Virginia $(\$ 1,960)$, Nebraska $(\$ 1,955)$, Iowa $(\$ 1,947)$, and Nevada $(\$ 1,942)$. For these states, an increase in taxes would reduce in-migration rates.

We may relate our finding of voters' optimal tax value to the Tiebout (1956) model, though Tiebout (1956) mainly concerns voters' choice of jurisdictions to match their preferences with taxes and government services (education and others) within a metropolitan area. Our finding suggests that the relation between interstate in-migration and tax burdens is more complicated than those proposed by Tiebout (1956) and Cebula (1990). Voters and consumers are willing to pay local and state taxes up to the optimal level of $\$ 1,943$, beyond which interstate inmigration rates are expected to decline as tax burdens are raised. Note that this optimal value of $\$ 1,943$ is derived based on the 1990 data. It is expected to increase if we want to estimate a new figure for a more recent year.

\section{Suggestions for Future Research}

There are some limitations of this paper. Because state data are used, individual characteristics can not be examined, and important information may be lost (Navratil and Doyle, 1977). Due to lack of data, quality of life variables except for the crime rate can not be considered. Future research may consider the use of individual or MSA data to study the determinants of interstate migration so that life-cycle or family characteristics and other potential variables may be considered.

I am grateful to the College of Business at Southeastern Louisiana University for providing a summer release time grant and valuable support of this research project.

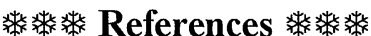

1. Becker, Gary S., "Investment in Human Capital: A Theoretical Analysis," Journal of Political Economy, Supplement, Part 2, 70, pp. 9-49, 1962.

2. Human Capital, Columbia University Press, New York, 1975.
3. Cebula, Richard J., "A Brief Empirical Note on the Tiebout Hypothesis and State Income Tax Policies," Public Choice, 67, pp. 87-89, 1990.

4. Greenwood, Michael J., "Research on Internal Migration in the United States: A Survey," Journal of Economic Literature, 13, pp. 397-433, 1975.

5. — "Human Migration: Theory, Models, and Empirical Studies," Journal of Regional Science, 25, pp. 521-544, 1985.

6. Herzog, Henry W., Jr., Richard A. Hofler, and Alan M. Schlottmann, "Life on the Frontier: Migrant Information, Earnings, and Past Mobility," Review of Economics and Statistics, 67, pp. 373-382, 1985.

7. Molho, Ian, "A Dynamic Model of Interregional Migration Flows in Great Britain," Journal of Regional Science, 24, 317-337, 1984.

8. Muth, Richard F., "Migration: Chicken or Egg," Southern Economic Journal, 37, pp. 295-306, 1971.

9. Nakosteen, Robert A. and Michael Zimmer, "Migration and Income: The Question of SelfSelection," Southern Economic Journal, 46, pp. 840$851,1980$.

10. Navratil, Frank J. and James J. Doyle, "The Socioeconomic Determinants of Migration and the Level of Aggregation," Southern Economic Journal, 43, pp. 1547-1559, 1977.

11. Porell, Frank W., "Intermetropolitan Migration and Quality of Life, Journal of Regional Science, 22, pp. 137-158, 1982.

12. Sandell, Steven H., "Women and the Economics of Family Migration," Review of Economics and Statistics, 59, pp. 406-414, 1977.

13. Schlottmann, Alan M. and Henry W. Herzog, Jr., "Employment Status and the Decision to Migrate," Review of Economics and Statistics, 63, pp. 590-598, 1981.

14. Tiebout, Charles M., "A Pure Theory of Local Expenditures," Journal of Political Economy, 64, pp. 416-424, 1956. 